PALABRAS CLAVE

Política industrial

Empresas industriales

Organización industrial

Regionalismo

Chile - Uruguay
Andrés Rivarola

Investigador asociado al

Departamento de Historia

Económica y al Instituto

de Estudios Latinoamericanos

de la Universidad de Estocolmo

œ andres.rivarola@ekohist.su.se
REVISTA DE LA CEPAL 91 • ABRIL 2007

\section{Espejos de cambios: empresarios industriales en Chile y Uruguay}

\author{
Andrés Rivarola
}

$\mathrm{E}$

ste estudio examina los cambios institucionales en Chile y Uruguay entre mediados de los años 1960 y fines de los 1990. Intenta ligar los niveles macro y micro y, a partir de ellos, observar la adaptación o conflicto entre instituciones ligadas a lo global y lo local, desde la perspectiva de dos asociaciones de empresarios industriales: la Sociedad de Fomento Fabril (SFF) en Chile y la Cámara de Industrias del Uruguay (CIU). Desde esta perspectiva se analiza en qué forma la 'lógica de lo apropiado' de las organizaciones se ha modificado desde los años 1960, esperando ver cambios en la interacción de fuentes de legitimidad a nivel global, regional y nacional. Para hacer más visible el proceso de cambio se hace hincapié en dos años: 1966 y 1998. El artículo busca también encontrar nuevas dimensiones de comparación entre los procesos de desarrollo en Chile y Uruguay. 


\section{I}

\section{Introducción}

A partir de los años 1990 ha tomado fuerza el trabajo de institucionalistas para quienes la elección racional (rational choice) es una perspectiva demasiado estrecha para explicar conflictos de interés en la sociedad (Hart, 1995). Una vertiente de este enfoque proviene de la teoría de organizaciones en ciencias sociales que tiene como uno de sus puntos de partida la obra de Selznick (1949). Dicho autor sostenía que las organizaciones no son las "criaturas racionales", sino vehículos que encarnan valores, y argumentaba que los valores y las normas organizacionales se trasmiten a través del ambiente institucional en el cual están insertas. Desde esta perspectiva, se define una organización como la función de los intereses legitimados que se transmiten a través del 'ambiente institucional'. Este ambiente se caracteriza por la elaboración de reglas y exigencias institucionales a las cuales las organizaciones deben adaptarse para ser legitimadas. Una institución es vista como un 'patrón social' que rige determinadas normas de conducta y pensamiento, y la institucionalización de una organización ocurre cuando intenta validarse a través del esfuerzo por imitar otros modelos considerados superiores (Powell y DiMaggio, 1991). Esto va de la mano con lo que March y Olsen (1989) denominaron la 'lógica de lo apropiado', según la cual es posible imponer reglas, más allá de la coerción directa, imponiendo códigos de comportamiento.

Siguiendo esta línea de pensamiento, miraremos a los gremios empresariales como un punto de intersección institucional que permite observar la interacción de tres niveles institucionales: nacional, regional y global. Los límites entre estos niveles no son fijos, por lo cual señalar a organizaciones o instituciones como pertenecientes a uno no implica que no puedan actuar también en otros. Este estudio postula que ha habido un cambio en el ambiente institucional nacional durante el período posterior a la segunda guerra mundial. En este período se ha acentuado la influencia de instituciones globales y regionales, proceso claramente visible en los años 1990 con la globalización. Hay quienes se refieren a esto como el Imperio (Hardt y Negri, 2000); nosotros preferimos hablar de la expansión de una 'cultura global' (world culture), que promueve valores y modelos estandarizados. Estos están centrados en 'lo técnico' (racional) y en una cultura de los derechos humanos (Boli y Georg, 1999) promovida por una cantidad de entidades inter- nacionales, fundamentalmente en torno al sistema de las Naciones Unidas. El regionalismo ha sido parte de este proceso, pero ubicándose a un nivel meso, como forma de confrontar la globalización (Hettne e Inotai, 1997). Todo esto ha erosionado de manera creciente a los Estados-nación, lo que se ha traducido en nuevas fuentes de 'legitimidad' proveniente de esferas no nacionales de autoridad (Rosenau, 2003).

Una segunda hipótesis es que los cambios estructurales tienen efectos distintos a nivel local, dado que cada ambiente institucional crea formas propias de 'isomorfismo institucional' (mimetismo) o de resistencia. Tanto en el caso chileno como en el uruguayo se observan formas propias de adaptación, con líneas de continuidad y cambio en 'lo local'. Es claro que esta comparación, como todas, debe ser relativizada según las preguntas, variables y actores elegidos. De cualquier manera, se espera que las conclusiones de este trabajo aporten al entendimiento de los cambios y continuidades institucionales, tanto entre los países como entre instituciones a nivel micro y macro. Se espera asimismo que el enfoque de este estudio permita encontrar otros factores que contribuyan a explicar las diferentes trayectorias de desarrollo en Chile y Uruguay. Ambos países fueron durante décadas las democracias más estables de Sudamérica, con un desarrollo vigoroso del aparato estatal y fuerte crecimiento del sector industrial. En los años 1990, ya otra vez con gobiernos democráticos, Chile se distanció claramente de Uruguay como modelo 'exitoso' de 'cómo hacer las cosas' en un mundo globalizado.

Tras la presente sección introductoria, este estudio se aboca a un breve examen de formas de organización y políticas industriales que señalan las líneas históricas en cada ambiente institucional (sección II). Luego se centra en la década de 1960, en la cual se explora la 'lógica de lo apropiado' en la primera ola institucional de la cultura global (sección III). En la sección IV se pasa revista a lo que se ha llamado aquí el 'interludio militar', como base para comprender mejor ciertos patrones de cambio en los años 1990. En la sección V se analiza el decenio de 1990, y en la sección VI, por último, se presentan algunas conclusiones.

El interludio militar significó un corte en la influencia de determinadas entidades internacionales, 
que fue retomada en un contexto marcado por la liberalización de los mercados y el renovado influjo de la cultura global. En el análisis de la década de
1960 y el de la década de 1990 se utilizó igual estructura de trabajo, con el fin de hacer más visible la comparación.

\section{II \\ Primeras formas de organización y políticas industriales}

El primer impulso de organización de los industriales uruguayos surgió con la creación de La Liga Industrial, en 1879 (Jacob, 1981). Esta tuvo corta vida y confrontó una oposición hostil por parte de los defensores del libre comercio: los terratenientes agrarios y la elite comercial de Montevideo. Como indica la palabra 'Liga', se trataba de un conglomerado suelto de diferentes sectores de asociaciones bastante débiles. El debate en torno a una nueva ley de aduanas estimularía el establecimiento de la Unión Industrial Uruguaya (UIU) en 1989 (Ferrando, 1989), movilizando a los viejos miembros de la Liga en defensa de ideales proteccionistas. El sector industrial tomó fuerza en esta época, debido al crecimiento de la actividad industrial y a la creciente influencia de José Batlle y Ordóñez y del 'batllismo'. ${ }^{1}$ La mayor parte de los miembros de la UIU eran pequeños propietarios de talleres, ya que había muy pocas grandes plantas manufactureras en el país. No había nombres de familias oligárquicas en las filas de la UIU. Había sí gran participación de diferentes grupos de inmigrantes (Beretta Curi y Etcheverry, 1998). Otro elemento que cabe subrayar es la escasa participación del Estado en la fase inicial de la organización de industriales. No obstante, muchos de los miembros más jóvenes de la asociación se convirtieron luego en los políticos más importantes del país. Un ejemplo es el mismo Batlle y Ordóñez, periodista de La Liga Industrial, y otro José Serrato, técnico en la UIU. $^{2}$ Con el avance del batllismo los empresarios fueron incluidos en el sistema de toma de decisiones, lo que motivó cambios organizacionales encaminados a lograr una efectiva representación empresarial. Así, en 1914 se fundó la Cámara de Industrias del Uruguay, con el fin de crear una estructura más centralizada y eficiente. Se mantuvo el nombre de UIU, en tanto que algunos docu-

\footnotetext{
${ }^{1}$ Batlle fue Presidente de la República en los períodos 1903-1907 y 1911-1915.

${ }^{2}$ Serrato fue Presidente de la República en el período 1923-1927.
}

mentos y declaraciones se firmaban con el nombre de 'Cámara de Industrias del Uruguay, Corporación Líder de la Unión de Industriales del Uruguay'. Recién en 1973 se oficializó el nombre de Cámara de Industrias del Uruguay como único nombre de la Cámara.

En Chile, la situación fue muy distinta. Ya hacia fines del siglo XIX la Guerra del Pacífico generó una fuerte demanda estatal de industria pesada. Antes del conflicto el sector manufacturero chileno consistía en un pequeño número de fábricas aisladas y una gama de pequeños talleres. Con la obtención de grandes depósitos mineros, tanto la minería como la construcción de vías férreas estimularon el establecimiento de industrias pesadas a través de su creciente demanda de locomotoras y equipamiento (Kirsch, 1977). La industria chilena emergió así estrechamente relacionada con el Estado, bajo protección arancelaria, o directamente como propiedad estatal. A diferencia del caso uruguayo, la fundación de la Sociedad de Fomento Fabril (SFF) fue acompañada por una iniciativa oficial para apoyar activamente su creación. El ministro de finanzas le solicitó a la Sociedad Nacional de Agricultura (SNA) que apoyara la creación de una asociación que representara los intereses de los fabricantes nacionales (Ceppi, Sanhueza y otros, 1983). De este modo, en 1883, bajo la égida del Estado, se crea la Sociedad de Fomento Fabril (Zeitlin 1984), una organización modesta que debía reunirse en el local de la SNA (Apey, 1988). El apoyo de la SNA demuestra que, a pesar del crecimiento de la industria, no había confrontaciones serias entre intereses rurales e industriales.

El papel de la SFF cobró más importancia cuando la industrialización se transformó en una política de Estado, a través de entidades como la Corporación de Fomento a la Producción (CORFO), creada en 1939. No es casual que la iniciativa de crear la SFF viniera 'desde arriba', desde el Estado, el mismo que centralizara las políticas industriales vía CORFO, con su predominancia 
técnica respetada y emulada por los empresarios. Esto se ve como parte de dos instituciones características en Chile: el elitismo y la meritocracia. Chile se aisló de las guerras civiles del Cono Sur, dando continuidad y fortaleza a un aparato estatal de estructura jerárquica dominado por la oligarquía, a una burocracia estatal meritocrática y a una clase política con interés en un Estado fuerte.

La consolidación estatal uruguaya, y la de su oligarquía, es mucho más tardía. Quizás eso explique por qué la CIU crece 'desde abajo'. Si bien logra su institucionalización con el batllismo, los contactos con el Estado fueron tan fragmentados como las políticas industriales, cuando estas existieron. Más allá de la enorme trascendencia que tuvo Batlle, en Uruguay no hubo 'políticas' sino 'impulsos', determinados por los liderazgos de turno y las redes personales. De ahí que aparezcan como instituciones predominantes el caudillismo y el clientelismo. La diferencia entre caudillismo (Uruguay) y elitismo (Chile) reside en que mientras el primero tiene más que ver con 'carisma', que opera horizontalmente a través de los grupos sociales, el segundo se basa en una estructura más vertical, en la cual se segmenta un orden jerárquico por medio de grupos dominantes. Nada de esto significa que los elementos salientes de un caso no existan en el otro. Simplemente se señala aquí lo que parece característico de cada ambiente institucional.

\section{III}

\section{La década de 1960}

\section{Uruguay}

Durante la primera mitad del siglo XX la CIU se transformó en una organización sólida y cada vez más influyente, proceso que estuvo ligado al fuerte avance de la industria y al fortalecimiento de grupos económicos. Aproximadamente la mitad de los grupos industriales uruguayos se formaron entre 1933 y 1954 (Zurbriggen, 1999). En 1966 eran miembros de la CIU unas 20.000 compañías con alrededor de 500.000 empleados (El Día, 1966). La Asamblea General era la instancia más representativa, donde se elegían los miembros del Directorio por medio de listas, sin elección individual. Un número importante de miembros provenía de asociaciones gremiales sectoriales, a las cuales se les exigía que todos sus integrantes estuvieran registrados como miembros de la CIU, aunque esto era algo que no se controlaba estrictamente. Las asociaciones gremiales participaban también en el Directorio, sin derecho a voto. Más aún, un criterio para la selección de candidatos era que representaran a personas de diferentes sectores con experiencia previa en una asociación gremial. Los miembros del Directorio eran electos por tercios, lo cual hacía que los cambios fueran graduales. Todo esto confluía en poca confrontación, ya que las diferentes asociaciones gremiales (y las grandes compañías) generalmente acordaban una lista común de candidatos. Este sistema aseguraba la estabilidad en la dirección de la CIU, al tiempo que disminuía la participación y el debate interno. Así, el dominio de las grandes empresas le daba a la CIU la imagen de un 'club de grandes industriales'. En la Asamblea General de 1966 solamente 49 compañías participaron en la elección (CIU, 1966). Más allá de las gremiales, el Directorio tenía mucha influencia, ampliada a través de las comisiones de trabajo. Los presidentes de comisiones eran miembros del Directorio, pero debían ser aprobados por la Asamblea General.

En la Memoria anual 1966-1967 de la CIU se ve que la mayor parte del espacio estaba dedicado a información acerca de contactos con autoridades públicas, respecto a asuntos aduaneros o tipos de cambio (CIU, 1966). No es raro entonces que las dos unidades nacionales más mencionadas fueran el Ministerio de Industria y el (estatal) Banco de la República Oriental del Uruguay. La CIU tenía poco que ofrecer en términos de servicios y no prestaba particular atención a las pequeñas y medianas empresas (pymes), lo que afianzaba la imagen de la Cámara como entidad de elite y quizás contribuía a la escasa participación en las elecciones internas. Respecto al perfil de los miembros del directorio, según vemos en la memoria anual citada, aproximadamente la mitad carecía de títulos académicos (un perfil parecido al de los ministros de industria de la época). De aquellos que sí contaban con este tipo de calificación, la mayoría carecía de formación orientada a lo económico o lo tecnológico. Había un general retirado, un médico y dos abogados. De lo que podrían ser profesiones más cercanas a la actividad industrial, había dos ingenieros y un contador. El bajo 
nivel profesional era una característica común con la administración pública uruguaya (CIDE, 1989). El país no contaba con un plan de capacitación de funcionarios, y cuando algo se implementó en este sentido, poco se tuvo en cuenta al sector privado. Las empresas seguían siendo de propiedad familiar (generalmente inmigrantes de primera o segunda generación) que producían bienes de consumo para el mercado local. Aunque algunas habían crecido hasta formar oligopolios (con protección estatal), carecían de incentivos para cambiar. Los hijos siguieron a los padres sin modificar los perfiles gerenciales, siendo este quizás la causa de que la mayor parte de los miembros del directorio fueran propietarios y no gerentes profesionales. No había tampoco interés en cambiar: los canales con el Estado aseguraban los negocios y la relevancia de la CIU no se discutía.

\section{a) Nivel nacional}

Los contactos más frecuentes de la CIU eran con el Ejecutivo. Especialmente con el ministerio de industria, al cual los industriales se dirigían para pedir distintos tipos de intervenciones estatales. Pero este ministerio hacía poco en términos de políticas industriales, y carecía de capacidad técnica y de coordinación para promover políticas eficientes. Si la formación profesional se tomara como un indicador de 'capacidad técnica', los antecedentes de los ministros resultan elocuentes. Entre 1907 y 1996 hubo solo un economista, cinco contadores y cuatro ingenieros; el resto eran abogados, o personas sin calificación académica (MIEM, 1997). Pocos venían del sector privado. El perfil de los ministros sugiere un fuerte dominio partidario, por encima de las capacidades técnicas. Otra entidad importante dentro del Estado era el Banco de la República Oriental del Uruguay, que tuvo el monopolio del mercado de moneda extranjera y el control sobre los tipos de cambio diferenciados. Una entidad clave de este banco era la Unidad de Contralor de las Operaciones de Cambio y Traslados de Capitales al Exterior. Aunque el banco vio deteriorarse su posición con las reformas liberales de comienzos de los años 1960, a mediados de la década seguía desempeñando un papel relevante.

Otros puntos de intersección entre los industriales y el Estado eran las diferentes comisiones que funcionaban como lugares de encuentro entre lo público y lo privado. $\mathrm{Si}$ bien estas no eran mencionadas frecuentemente en los informes de la CIU, sus actividades pueden servir para señalar las áreas donde los empresarios ejercían influencia. Dos ejemplos son la Comisión Asesora de Reintegros y la Junta de Aranceles. Si bien la CIU influyó poco en la formulación de políticas, tuvo mucho que decir sobre reintegros y cuotas de importación. Un aspecto de especial interés en la interacción con el Estado fue la versión uruguaya del impulso desarrollista: la Comisión de Inversiones y Desarrollo Económico (CIDE), creada en enero de 1960. Esta comisión contaba con personal técnico de alto nivel y su trabajo tuvo efectos a nivel empresarial. Contrariamente a la percepción corriente de que los industriales son 'clientelistas' o 'cortoplacistas', hubo esfuerzos serios del sector por entregar propuestas propias en sintonía con la CIDE. Lo más destacado fue la creación de la Comisión Coordinadora para el Desarrollo Económico (COMCORDE), en 1963. El aura que rodeaba la creación de la CIDE fue una fuente de inspiración fundamental para los miembros de la COMCORDE. ${ }^{3}$ Aproximadamente cincuenta técnicos pasaron por esta comisión coordinadora, una de las primeras organizaciones del país que contrataron economistas. Luego de la disolución de la CIDE en 1967, hasta su propio cierre en 1981, la COMCORDE produjo una serie de trabajos sobre planificación indicativa y análisis sectoriales. Siendo la CIDE un proyecto modernizador con visión global de largo plazo, la CIU claramente la apoyó. Por otra parte, queda también de manifiesto que la CIDE dependía mucho del Estado. Cuando este perdió interés en el impulso desarrollista, los empresarios no lograron mantener la nueva línea y volvieron a las viejas rutinas.

\section{b) Nivel regional y global}

La mayoría de las menciones a entidades no nacionales en la Memoria anual 1966-1967 se refieren a organizaciones regionales, y en especial a la Asociación Latinoamericana de Libre Comercio (ALALC), creada en 1961. Originalmente los empresarios manifestaron cierta apatía ante esta iniciativa, en la que participaron por invitación del gobierno y no por iniciativa propia (Finch, 1973). Tampoco fueron muy entusiastas los esfuerzos oficiales por comprometer al sector privado. En cuanto a la CIU, Astori (1980) sostiene que la Cámara percibía el área de libre comercio más como una amenaza al sistema proteccionista uruguayo que como un cambio en el contexto internacional que apuntara a incrementar las exportaciones industriales. No sorprende entonces la ausencia de la Cámara en las comisiones preparatorias para el acuerdo de la ALALC. Hacia 1966 el escepticismo de la Cámara había disminuido marcadamente: se sostenía que la ALALC era de importancia crucial para Uruguay y se señalaba la necesidad de atender más al tema de la

\footnotetext{
${ }^{3}$ Entrevista a Walter Luciardo Aznares, secretario técnico de la CIU en 1966.
} 
integración y a la adopción de una política de largo plazo. Aparte de lo comercial, interesaban a los industriales las nuevas formas de redes internacionales de empresarios que emergieron en torno a las negociaciones: por ejemplo, la Asociación de Industriales Latinoamericanos (AILA). Entidades regionales de este tipo contribuyeron mucho a promover nuevas formas de identidad empresarial que desempeñaron un papel clave en la adopción de una postura positiva frente a la ALALC.

A pesar del 'cambio de actitud' ante la integración, poco varió la estructura organizativa de la $\mathrm{CIU},{ }^{4}$ y la ALALC fue apenas mencionada en la Memoria anual 1966-1967, quizás porque nunca se adoptó la orientación exportadora como una meta clara de la CIU. Solo a mediados de los años 1970 se creó una comisión de comercio exterior en la CIU, con muchas discusiones internas acerca del avance de las reuniones sectoriales, los acuerdos complementarios y los programas regionales para empresarios. Si bien la CIU tenía un bajo perfil dentro del proceso de la ALALC, las asociaciones gremiales sectoriales y las grandes empresas fueron más activas. Puesto que el Estado no contaba con las herramientas necesarias para obtener la información necesaria, los empresarios tenían un papel clave en las cuestiones de preferencias o concesiones que Uruguay negociaba con otros países. Las solicitudes de información pasaban por la CIU o directamente a través de las asociaciones sectoriales. Desde ese punto de vista sí sería correcto decir que tenían influencia. Otra parte del proceso en torno a la ALALC estaba relacionada con la actividad de la Asociación de Industriales Latinoamericanos (AILA). Luego de un período inicial más entusiasta, en 1966 la CIU se tornó escéptica, argumentando que la AILA tendía a la burocratización y sobrepasaba las posibilidades económicas de sus miembros (La Mañana, 1966).

En la Memoria anual 1966-1967 de la CIU se mencionan solo dos foros internacionales (el Congreso Lanero Mundial y la Conferencia Internacional del Trabajo) que indican algún tipo de compromiso. También se menciona dos veces el Instituto Uruguayo de Normas Técnicas (UNIT), fundado en 1939. Si bien este era un organismo nacional (privado pero con apoyo estatal), rápidamente se convirtió en representante de la institucionalidad internacional en su trabajo con normas de calidad. No había mucho interés entre los empresarios por las mejoras de calidad, de modo que el UNIT apenas fue mencionado. Es interesante comprobar que el organismo internacional talvez más importante para el sector

\footnotetext{
${ }^{4}$ Entrevista a Carlos Folle, gerente de la cIU en 1966.
}

industrial, el Banco Interamericano de Desarrollo (BID), no fuera mencionado en la memoria anual indicada. Esto puede deberse al escaso contacto formal de la CIU con el BID, que operaba fundamentalmente a través del Estado y, en especial, del Banco de la República Oriental del Uruguay. En general, es poco lo que podría escribir la CIU acerca de las organizaciones regionales o globales en esa época.

\section{Chile}

El perfil técnico de los miembros del Comité Ejecutivo de la SFF nos da la pauta de la diferencia entre los ambientes institucionales de Chile y Uruguay. La mayoría eran profesionales, todos ingenieros. Tampoco en el caso chileno parecen haber sido frecuentes los títulos extranjeros: solamente un miembro del comité lo tenía. La mayor parte de los miembros ocupaban cargos en el aparato estatal, como era el caso de los representantes de la SFF en los directorios de la CORFO y del Banco Central de Chile. Un elemento común con la CIU era que los miembros del Comité Ejecutivo de la SFF provenían fundamentalmente de las grandes empresas. Por otro lado, el directorio de la SFF tenía más participación de gerentes, quizá porque Chile contaba con un sector industrial más desarrollado donde los gerentes profesionales (no los propietarios tradicionales) representaban a las empresas en mayor grado. La fuerte presencia de las grandes empresas (representadas por propietarios o por gerentes) en la dirección de la SFF acentuaba la imagen de esta como representante de los grupos económicos. Lo que Arriagada (1970) llamaba la "tendencia oligárquica" quedaba asegurada por estatutos que no permitían el voto por listas, impidiendo así la creación de grupos electorales. Al mismo tiempo, las asociaciones gremiales contaban con un voto cada una en el Comité Ejecutivo, lo que no reflejaba su verdadero peso en la SFF. Por ejemplo, la Asociación de Industriales Metalúrgicos (ASIMET), que representaba un 17,5\% de los miembros, solo tenía un asiento en el Comité. Más aún, $28 \%$ de los miembros del Comité Ejecutivo eran honorarios, y los ex presidentes mantenían un lugar vitalicio. Según Arriagada (1970), estos elementos en su conjunto favorecían las tendencias oligárquicas que beneficiaban a los grupos económicos.

\section{a) Nivel nacional}

Si bien la ALALC fue la entidad más mencionada en la Memoria anual de la SFF 1966-1967 (SFF, 1966), los contactos principales de esta sociedad fueron con las entidades nacionales en su conjunto, fundamentalmente 
con las del Estado, en especial la CORFO, el Banco Central y el Parlamento. Con respecto a la CORFO, dicha memoria anual cuenta sobre contactos en los cuales la SFF reclamaba reducción arancelaria a las importaciones para equipamiento industrial. Otra mención está relacionada con reclamos de las asociaciones gremiales regionales referidos a dificultades con créditos y pagos de deudas. Estas solicitudes eran presentadas a la dirección de la SFF y luego transmitidas directamente a la CORFO. En lo que respecta al Banco Central, una preocupación importante tenía que ver con las cuotas de importación. También fue mencionado en el debate acerca de una ley sobre fomento a las exportaciones. En cuanto a la interacción con el Parlamento, al que asignaba más importancia que la CIU, la SFF contaba con un grupo asesor para cuestiones parlamentarias al que los miembros podían solicitar asesoramiento y contacto con los políticos. En SFF (1966) se da cuenta de que la asociación expresó su opinión acerca de las modificaciones de la ley que asignaban un tratamiento arancelario especial al Departamento de Arica. El Parlamento fue también mencionado en relación con la ley para promover la industria automovilística en Chile y las modificaciones constitucionales dirigidas a "debilitar el derecho efectivo a la propiedad privada". Esto estaba, en parte, relacionado con un fuerte debate sobre la reforma agraria.

Con respecto a la participación en comisiones estatales, al igual que la CIU, la SFF participaba de manera institucionalizada en la estructura de sustitución de importaciones. Contaba con representación en entidades estatales como el Banco del Estado, la CORFO y la Junta General de Aduanas. En estas instancias, los empresarios se ocupaban principalmente de temas concretos como precios, control de cambios o leyes específicas. Más allá de esta participación, no se notaba una propuesta económica propia de los empresarios. Cada uno estaba fundamentalmente preocupado de su propio sector, dejando al Estado la iniciativa de elaborar políticas económicas y sociales. Esto no significó que no intentaran crear sus propios instrumentos de análisis. En 1954 un grupo de empresarios fundó el Instituto Chileno de Administración Racional de Empresas (ICARE). Las personas que estaban detrás de esta iniciativa se veían como 'empresarios progresistas' y sus líderes eran principalmente de la SFF (Empresa, 1968). Aun cuando el ICARE mostró que había iniciativa para crear centros propios de investigación, al mismo tiempo daba señales de estrecha interacción con el Estado. Funcionarios muy conocidos y partidarios del Partido Demócrata Cristiano, como Raúl Sáez y Gabriel Valdés, se convirtieron en presidentes del instituto. Hasta 1968 casi todos los presidentes del ICARE habían ocupado cargos públicos, la mayor parte como ministros o embajadores.

\section{b) Nivel regional y global}

$\mathrm{Al}$ igual que en el caso de la CIU, la entidad internacional más mencionada en la Memoria anual 1966-1967 de la SFF era una de carácter regional: la ALALC. La participación de la SFF dentro del esquema de la ALALC era también similar a la de la CIU: ambas daban el sí o el no a productos negociados. Sorprende en el caso chileno que la ALALC fuera mencionada más frecuentemente que la CORFO, ya que los industriales no estaban orientados hacia las exportaciones. Una razón podría ser que Chile era uno de los países más activos en torno a las ideas de integración. No es casualidad que la oficina central de la Comisión Económica para América Latina $(\mathrm{CEPAL})^{5}$ estuviera en Santiago de Chile, ni que varios de los grandes pensadores cepalinos fueran chilenos. También los industriales eran entusiastas respecto a las iniciativas de la CEPAL, como lo fue la ALALC. En 1961, durante la Reunión Anual de la Convención Nacional de la Industria de la SFF, se expresó un firme apoyo al proceso de integración y se decidió crear una Comisión del Área de Libre Comercio en la SFF, cuya actividad sería coordinada en forma conjunta con el gobierno. Pero la opinión no era unánime, ya que las empresas de la industria liviana (este era el caso de la mayor parte de la industria uruguaya) tendían más bien a oponerse a la idea, por temor a la competencia regional (Mikesell, 1961). A pesar de esto, la SFF era una de las fuerzas promotoras de la ALALC. Quizás se pueda ligar esto a su imagen de organización de elite, aunque muchos de los entusiastas fueran también celosos de las protecciones arancelarias. Había otra dimensión de la ALALC que iba más allá de los cálculos económicos.

Los empresarios eran muy dependientes de un Estado que realizaba grandes avances en el sector industrial. Esto era visto con suspicacia por el liderazgo de la SFF, cuya posición se estaba debilitando debido a los éxitos de la CORFO y sus 'empresarios públicos'. En este contexto, las declaraciones pro sector privado de los organismos de integración regional y sus redes empresariales anexas funcionaban como contrapeso al creciente 'estatismo'. La estrategia de los empresarios chilenos fue buscar fortaleza ideológica y legitimidad a través de estos organismos, para promover la idea de que Chile necesitaba el sector privado. Es quizá por este

\footnotetext{
${ }^{5}$ Hoy Comisión Económica para América Latina y el Caribe (CEPAL).
} 
motivo que la SFF se mostró más favorable a la AILA que la CIU. Obsérvese que al mismo tiempo que la CIU denunciaba a la AILA como una organización burocrática e innecesaria, la SFF hacía declaraciones más positivas que abogaban por una mayor participación institucionalizada del sector privado en las negociaciones. El BID, bajo el liderazgo del chileno Felipe Herrera, brindó mucho apoyo a Chile, pero tuvo escaso contacto con la SFF. La Memoria anual 1966-1967 de la SFF informa de la donación por el BID de una valiosa biblioteca de economía a la SFF y relata la participación de empresarios chilenos en una conferencia sobre integración regional financiada por el banco. La SFF parecía tener algo más de contacto con el BID que la CIU, pero esto no debe atribuirse solamente a un patrón específico de los empresarios. En realidad, el Estado fue la principal fuerza articuladora en el ámbito regional y global. Ya en los años 1950 comenzó a enviar funcionarios a estudiar al extranjero y fortaleció los lazos con universidades de los Estados Unidos y Europa. Por otra parte, Chile era uno de los países predilectos de los organismos internacionales, siendo el más favorecido en términos de dólares per cápita (El Mercurio, 1966). Un impulso importante en este sentido surgió de la interacción con la CEPAL, el organismo internacional que más influyó en la difusión del enfoque tecnocrático en las esferas del Estado y en los círculos empresariales, por medio de la planificación indicativa. Claramente, aquí se ven los ingredientes de la primera ola de la cultura global en el ambiente institucional chileno.

\section{IV}

\section{El interludio militar}

En Uruguay el golpe de estado provino de un presidente constitucional, apoyado por los militares, de modo que hubo continuidad de las políticas económicas y de los actores dirigentes. Como explica Faroppa (1982), las bases del modelo iniciado en 1973 eran las mismas que habían sido adoptadas poco antes por el gobierno civil, es decir, el Plan Nacional de Desarrollo 1973-1977, elaborado por la Oficina de Planeamiento y Presupuesto. El propio ministro de economía del régimen, Alejandro Vegh Villegas, cuenta que cuando asumió tomó como base de acción el plan elaborado por Ricardo Zerbino y Alberto Bensión. ${ }^{6}$ Tanto Zerbino como Bensión se convirtieron posteriormente en ministros de los gobiernos posdictatoriales, de modo que se puede hablar de una continuidad en el diseño de las políticas económicas. Dos de las principales iniciativas del ministerio de Vegh ya estaban firmadas cuando él llegó al poder: el Convenio de Cooperación Económica entre Uruguay y Argentina (CAUCE) y el Protocolo de Expansión Comercial UruguayBrasil (PEC). Estos acuerdos fueron de gran importancia para el sector manufacturero, y especialmente para la CIU. Esta adquirió una posición institucionalizada en el nuevo sistema comercial, con el monopolio para la emisión de certificados de origen de las exportaciones

\footnotetext{
${ }^{6}$ Entrevista a Alejandro Vegh Villegas, Ministro de Economía en 1974-1976 y en 1983-1985.
}

en virtud del CAUCE y el PEC, con lo cual obtuvo una nueva y muy importante fuente de ingresos.

En Chile, cuando los militares tomaron el poder, el Estado controlaba casi todo el sistema bancario, más de 323 empresas habían sido confiscadas o eran supervisadas y grandes extensiones de tierra eran administradas por cooperativas. Durante 1972 las exportaciones habían alcanzado un nivel mínimo, la inflación llegó al $600 \%$ y los ingresos por concepto de exportaciones dependían en un $80 \%$ del cobre. Las asociaciones del sector privado se veían como participantes constitutivos de una revolución victoriosa y del nuevo régimen (Campero, 1984). Y seguían dando su apoyo aun cuando pronto fueron marginados del poder, por lo que Silva (1996) denominó la "coalición neo-liberal radical", e incluso cuando las fuertes rebajas arancelarias llevaron a la quiebra a importantes sectores empresariales. Finalmente, la severa crisis económica de 1982 eliminó esta corriente, sustituida por un grupo neoliberal pragmático con mayor participación empresarial. Tras sus duras experiencias, tanto con la Unidad Popular como con los 'Chicago boys', los empresarios comenzaron a desarrollar su propia capacidad técnica, adquiriendo un lenguaje común con la tecnocracia estatal.

En Uruguay, por su lado, se mantuvieron ciertos rasgos tradicionales. Luego de más de una década de gobierno militar, las políticas económicas culminaron 
en un instrumento destinado a construir una base de apoyo clientelista para los hombres de la dictadura (Stolovich, Rodríguez y Bértola, 1996). Fomentado por la propia estructura de la Junta de Generales, y distinto al centralismo de Pinochet, cada fracción de las fuerzas armadas tenía un poder de veto significativo, lo que abrió espacios para establecer grupos de presión y redujo la influencia de los técnicos estatales en la implementación de políticas públicas. Los militares no lograron consolidar caudillos. Lo que hicieron fue crear liderazgos sectoriales que impedían el funcionamiento de mecanismos centralizadores y llevaba al clientelismo. No hubo grandes cambios, tampoco entre los empresarios industriales.

\section{V}

\section{La década de 1990}

\section{Chile}

El tema del medio ambiente fue el que recibió mayor espacio en la Memoria anual 1998-1999 de la SFF. Casi inexistente en los años 1960, comenzó a tomar fuerza en 1992, con la aparición del primer programa ambiental del Estado, el Plan de Descontaminación de la Región Metropolitana. Pocos años después había ya 10 programas nacionales. Si bien el área ambiental adquirió gran relevancia para los industriales, solamente ocupó a una pequeña porción del personal de la SFF. Una razón para esto fue el importante apoyo técnico que le brindaban las empresas asociadas. La tarea de la SFF, por lo tanto, se centraba en vigilar el proceso legislativo a través de comisiones especiales, en las cuales participaban expertos de las empresas. ${ }^{7} \mathrm{Un}$ segundo tema abordado en dicha memoria anual fue el de las relaciones internacionales y comercio exterior. Podría decirse que el área de comercio exterior adquirió más relevancia de dos maneras: a través de la participación en negociaciones comerciales y por medio del trabajo con organismos de promoción comercial (servicios). La SFF se convirtió en la 'secretaría técnica' del sector privado, en lo concerniente a negociaciones comerciales. ${ }^{8}$ Un tercer conjunto de temas fue abordado por el Área de Desarrollo Social, que no existía en 1966; los más importantes de esos temas surgían de los compromisos históricos de la asociación, como el vinculado a la educación industrial. En 1998 la SFF administraba 18 liceos técnicos en todo el país y se había convertido en uno de los Organismos Técnicos Intermedios de Capacitación (OTIC), en virtud de un

\footnotetext{
${ }^{7}$ Entrevista a Aníbal Mege Thierry, encargado del área ambiental de la SFF.

${ }^{8}$ Entrevista a Aníbal Mege Thierry.
}

programa estatal dirigido por el Servicio Nacional de Capacitación y Empleo (SENCE). La Memoria anual 1997-1998 habla también de la Corporación de Promoción para la Pequeña Empresa (PROPESA), que ofrecía préstamos blandos a las pequeñas empresas y organizaba programas de educación con el apoyo de recursos del Fondo de Solidaridad e Inversión Social (FOSIS), asignados por la CORFO.

La composición del Comité Ejecutivo de 1998, comparado con el de 1966, acusa dos tendencias: aumento de la profesionalización y concentración en las áreas económicas. En 1998, el 85\% del Comité estaba constituido por profesionales, cifra que en 1966 era de $64 \%$. La mayor parte de ellos correspondía a ingenieros o a lo que en Chile se llama ingenieros comerciales. En 1998 también había más integrantes formados en el extranjero, casi todos titulados en universidades de los Estados Unidos. Entre 1996 y 1998 la proporción de gerentes en el comité subió de $63 \%$ a $70 \%$, mientras que los miembros con cargos públicos cayeron de $55 \%$ a $30 \%$. Otra característica era que más miembros estaban ligados a empresas pertenecientes a los grupos económicos.

\section{a) Nivel nacional}

La entidad más mencionada en la Memoria anual 1997-1998 de la SFF fue la Comisión Nacional del Medio Ambiente (CONAMA). Otro organismo público mencionado en relación con temas medioambientales fue el Servicio de Salud del Ambiente de la Región Metropolitana (SESMA), que tenía la responsabilidad de poner en práctica el Plan de Descontaminación de la Región Metropolitana. Esto era algo de suma importancia para los empresarios, ya que los efluentes de varias empresas iban a ser controlados por organismos públicos. El papel del SESMA era más bien reactivo, ya 
que la CONAMA constituía la fuerza directriz detrás de las nuevas reglamentaciones.

En cuanto a comercio exterior, hubo una explosión de servicios provenientes fundamentalmente del Estado chileno, que había mejorado sus mecanismos de coordinación interna (Comité Interministerial de Negociaciones Económicas Internacionales) y con el sector privado (Comité de Participación del Sector Privado). Un organismo clave fue la Dirección General de Relaciones Económicas Internacionales (DIRECON), dependiente del Ministerio de Relaciones Exteriores. Como explica Silva (2001), la relación entre la DIRECON y la SFF se transformó en un vínculo fundamental de interacción público-privada, dado que ambas eran unidades de coordinación en sus respectivos ámbitos. Otra unidad estatal de estrecho vínculo con la SFF era la Dirección de Promoción de Exportaciones, conocida como ProChile, ya que sus servicios promovían la inserción de empresarios chilenos en mercados internacionales. Aunque casi no hay menciones de la CORFO en la Memoria anual 1997-1998, muchos de los organismos gubernamentales o paragubernamentales que figuran en ella formaban parte de la red financiada por la CORFO. Durante la primera mitad de los años 1990, el monto total de los recursos transferidos a través de instrumentos públicos de financiación podía estimarse en unos 470 millones de dólares (Muñoz, 1997, p. 8). Aunque se criticó a los programas de apoyo público por su lentitud o ineficiencia, no hubo un rechazo de parte de los representantes de la SFF, entidad que incluso se había beneficiado financieramente del sistema. En cierto modo, la posición de la SFF recuerda la que se observó al crearse la CORFO, cuando se aceptó que el Estado se hiciera cargo de una mayor proporción de las políticas de promoción empresarial, confiando en que no se atentaría contra el derecho a la propiedad privada. La mutua comprensión con el Estado también podría encontrarse en el creciente tecnocratismo del sector público y privado. En la CORFO, casi todos los directores de programas eran economistas, muchos de ellos graduados en universidades estadounidenses. Lo mismo sucedía entre los altos ejecutivos del sector privado. En general, se observaba una relación algo 'promiscua' entre el sector público y el privado. Sin embargo, la participación de la SFF en estas estructuras de servicio pareció decaer hacia fines de los años 1990. En lugar de la SFF, la principal contraparte de la CORFO y el sector industrial pasó a ser una asociación sectorial de la SFF, la Asociación de Exportadores de Manufacturas de Chile (ASEXMA).

\section{b) Nivel regional y global}

La organización no nacional más mencionada en la Memoria anual 1997-1998 de la SFF fue el Mercosur (ocupó el quinto lugar en el total). Algo distinto a lo sucedido con la ALALC en 1966. Comparando las menciones realizadas en ambos períodos surgen otras diferencias interesantes. En los años 1990, los patrones de interacción entre la SFF y los niveles regional y global no estaban realmente dirigidos a organizaciones individuales sino a negociaciones y tratados de libre comercio, reflejo quizás de que Chile era el país latinoamericano con el mayor número de acuerdos comerciales, y de que la vocación exportadora aumentaba entre los empresarios. El espacio dedicado al comercio (incluido el Mercosur) en la memoria anual citada no refleja el enorme impacto de este tema en la estructura de la SFF. En los años 1960 la SFF actuaba como 'mensajeros en las negociaciones': recibía las listas de temas para negociar, las entregaba a las empresas correspondientes y luego pasaba sus respuestas al gobierno. ${ }^{9}$ En la década de 1990, el formato de las negociaciones era mucho más complejo: no solo estaban sobre la mesa casi todos los temas al mismo tiempo, sino que se negociaba con distintos países a la vez. Esto llevó a crear todo un nuevo sistema de interacción con el Estado, uno de cuyos precedentes fue el tratado de asociación con el Mercosur de 1997, que contenía cronogramas para la reducción universal de aranceles. La SFF, percibiendo que un acuerdo con el Mercosur era estratégico, le brindó su apoyo técnico y político. El proceso de asociación de Chile con el Mercosur también significó algo más que cálculos comerciales. Hubo un estrecho acercamiento entre representantes empresariales y tecnócratas del Estado en los complejos procesos de negociación. Otro aspecto, importante pero menor, fue el acercamiento de los empresarios de la región en virtud de su participación en organizaciones o redes propias del sector privado, por lo general en torno a acuerdos o negociaciones comerciales; entre ellas están el Consejo Industrial del Mercosur y la Red Empresarial para la Integración Hemisférica. El creciente interés en el comercio exterior determinó la formación de nuevos grupos de trabajo en la SFF, así como la incorporación de una red amplia de consultores y técnicos de las empresas.

Con respecto a los servicios, llama la atención la ausencia de agencias externas de cooperación en los documentos de la SFF. A pesar de que muchas eran

\footnotetext{
${ }^{9}$ Entrevista a Hugo Baierlein Hermida, director de comercio exterior de la SFF.
} 
sumamente activas en este terreno, prácticamente no se las mencionaba. En general, la SFF mostraba cierto rechazo a relacionarse con ellas. Aducía, por ejemplo, que no precisaba fondos de esas organizaciones porque trabajaba como una empresa privada, compitiendo en el mercado (en gran parte con financiamiento estatal). Es cierto que ya tenía poca interacción con agencias internacionales en los años 1960, pero sorprende que esto haya persistido pese a la creciente actividad local de tales organizaciones. Así, por ejemplo, la GTZ (Sociedad Alemana de Cooperación Técnica), ${ }^{10}$ una de las agencias de desarrollo más influyentes en Chile dedicada principalmente a ayudar a las pyme, no actuaba a través de la SFF, sino de la ASEXMA. Se atribuía a la SFF una concepción más bien autoritaria de las relaciones sociales y se la veía como defensora de las grandes empresas, con escasa representación entre las pyme. Algo parecido pensaban los representantes de dos importantes promotores de servicios a empresarios: el EUROCENTRO (financiado por la Unión Europea) y el BID. ${ }^{11}$

Uno de los elementos que más chocaban con la cultura global se manifestó durante el juicio a Augusto Pinochet en Inglaterra. Como señalara Tironi (1999, p. 59), la detención de Pinochet hizo que muchos empresarios chilenos se dieran cuenta de que la globalización anteriormente tan idealizada podía convertirse en una amenaza, y rápidamente comenzaron a satanizarla. Más aún, la detención de Pinochet demostró que la inserción de Chile en el mundo no era solamente económica, sino también moral, política y legal.

\section{Uruguay}

Si se compara el organigrama de la CIU en 1998 con el de 1966 se observa que la mayor parte de las comisiones que funcionaban en la década de 1960 han conservado su nombre. Pero saltan a la vista algunos nuevos temas, como el de comercio exterior. Si bien en 1966 ya existía la Comisión Asesora del Área de Libre Comercio, estaba casi exclusivamente ligada a la ALALC. En contraste, la Comisión de Comercio Exterior de 1998 fue considerada de importancia crucial para el sector, contaba con un espectro mucho más amplio de actividades y fue sin duda la comisión que atrajo mayor número de participantes (35 frente a un promedio de 15). Otra comisión nueva, la

\footnotetext{
${ }^{10}$ Deutsche Gesellschaft für Technische Zusammenarbeit.

11 Entrevistas a Francesca Di Micco, responsable del proyecto del eurocentro; a Vladimir Radovic, representante en Chile del BID, y a Peter Palesch, director de la agencia chilena de la GTZ y coordinador para todo el Mercosur.
}

de medio ambiente, exhibía un nivel de actividad mucho menor, talvez porque el Estado había trabajado muy poco en esta área, cosa que hacía desde la Comisión Técnica Asesora de la Protección del Medio Ambiente (COTAMA). Otra comisión que no existía en los años 1960 era la de relaciones con el 'interior' (territorio nacional fuera del área de Montevideo). Estar representada en todo el país siempre fue una meta de la Cámara, pero este era todavía un tema pendiente, pese a que Uruguay es un país relativamente pequeño. Entre las comisiones que se mantenían desde la década de 1960 se encuentra una relacionada con la ciencia, la tecnología y la calidad, quizás porque estos temas, junto con el de comercio exterior, atraían una mayor concentración de servicios y apoyo de entidades internacionales. Larga trayectoria tenía también la Unidad de Asuntos Económicos y Promoción de la Inversión. Aparte de lo que había hecho la COMCORDE, la CIU no contaba con mucha investigación propia. La década de 1990 trajo un interés renovado en este tipo de actividad, pero los estudios que surgieron no se abocaron a políticas de largo plazo sino que, mayormente, al trabajo con indicadores periódicos. Finalmente, la Comisión de Relaciones Sociales y Laborales también existía en 1966, pero este no era un sector muy activo de la CIU.

La directiva de la Cámara contaba en 1998 con un reducido número de profesionales, lo que se contraponía al nuevo perfil orientado a servicios y difería incluso de la composición de la directiva de 1966, que incluía más profesionales (CIU, 1998). Otro dato interesante es que en 1998 ninguno de los directivos parecía ocupar un cargo estatal. Este aspecto también contrastaba con 1966, cuando al menos dos tenían cargos en el Estado. En los dos años considerados ninguno de los miembros de la directiva tenía un título obtenido en el exterior. Si se supone que los miembros de la directiva son representativos del grupo líder de los empresarios industriales, se diría que el perfil profesional de estos era bajo, tanto respecto a los años 1960 como respecto a la SFF. En esta última no solo hubo un incremento de profesionales y gerentes, sino también de títulos obtenidos en el extranjero. Además de tener un bajo perfil profesional, la directiva de la CIU continuaba estando compuesto principalmente por dueños de empresas (con poca inserción internacional) y no por gerentes profesionales. Parecería que pese a intentos de reformas de corte liberal, la nueva generación de dirigentes empresariales uruguayos seguía surgiendo de un ambiente institucional que requería más destrezas sociales que profesionales. Esta característica fue señalada en un estudio de la CEPAL: en él se sostuvo que en Uruguay la mayoría de los contactos se iniciaban en 
forma individual, subrayando la importancia de confiar en las redes propias más que en aquellas alentadas por el Estado o cualquier otra organización (CEPAL, 1998). Pero el profundo impacto que tuvieron las crisis y la liberalización comercial sobre la industria hizo que muchas empresas grandes desaparecieran. Por lo tanto, el directorio de 1998 tenía una mayor representación de las pyme, lo que puede haber sido un incentivo para efectuar cambios. Una señal en ese sentido fue la elección de nuevas autoridades en 1992, a la que por primera vez en veinte años se presentaron diversas listas de candidatos. Según Zurbriggen (1999), en la elección participó casi el $50 \%$ de los miembros, en contraste con el 3\% (aproximadamente 50 miembros) que solía votar. Nuevas actores entraron en escena.

\section{a) Nivel nacional}

Uno de los organismos nacionales más mencionados en la Memoria anual 1998-1999 de la CIU era el Ministerio de Industria, Energía y Minería (MIEM), aunque este ya no constituía el 'ámbito de presión' de otrora, debido a la reducción de los aranceles y subsidios. Las reformas de los años 1990 asignaron a dicho ministerio el papel de coordinador de servicios y promotor de programas de apoyo a las pyme. No obstante, una proporción significativa de empresas no creía conveniente participar en programas relacionados con la formación de consorcios exportadores o diferentes tipos de redes, temiendo una excesiva burocratización (CEPAL, 1998). Incluso yendo más allá de los empresarios, se aducía la "fragilidad en la imagen del Ministerio". Como lo habían hecho Esser, Almer y otros (1983), también se señalaba la falta de lineamientos respecto a las políticas de promoción de la competitividad. Había incluso quienes argumentaban que el "MIEM en realidad no existe", señalando que era solo parte de un acuerdo partidario clientelista: si había un gobierno del partido blanco el ministro sería del partido colorado y viceversa.

Otra entidad muy mencionada era el Laboratorio Tecnológico del Uruguay (LATU). Se trataba del laboratorio tecnológico más importante del país, que estaba certificado según las normas de la Organización Internacional de Normalización (ISO) y era a la vez una organización certificadora del cumplimiento de dichas normas. Estaba asociado a calidad y a nuevas tecnologías, con lo cual contribuía a perfilar una imagen 'moderna' de la CIU. Entre otros organismos, trabajaron con el LATU el Centro de Gestión Tecnológica (CEGETEC) y el Servicio Nacional de Apoyo Empresarial (SENAE), fundamentalmente dirigidos a dar a las pyme asistencia técnica y orientación para la ejecución de proyectos. La tercera entidad nacional más mencionada era el Parlamento. Como vimos anteriormente, la CIU había creado una comisión para trabajar con temas legislativos. Según los empresarios, el Parlamento por lo general carecía de conocimientos acerca del sector industrial y prácticamente no había canales institucionalizados para intercambiar opiniones. Esta comisión procuraba seguir los aspectos legales referidos al sector y brindar apoyo a las asociaciones miembros de la CIU para presentar su posición o propuestas alternativas a los parlamentarios.

\section{b) Nivel regional y global}

Si bien la Memoria anual 1966-1967 de la CIU mencionaba más a organismos nacionales que a organismos internacionales o regionales, estos aumentaron considerablemente en el período 1966-1998. La entidad no nacional (y del total) más mencionada fue el Mercosur. Sin embargo, los empresarios uruguayos no mostraban demasiado interés en participar en el proceso de integración (Birle, Imbusch y Wagner, 1994). Es cierto que la aceptación del Mercosur por la CIU fue temprana, pero se basó más en la convicción de que no había otra alternativa, que en un verdadero espíritu regionalista o una ambición exportadora. Cuando las empresas, protegidas durante décadas, se dieron cuenta de la dura realidad de la rebaja arancelaria, el optimismo de la Cámara pasó a ser un "sí, pero....". La liberalización aumentaba la vulnerabilidad de la industria nacional, y mermaba los ingresos de la Cámara, por la disminución de certificados de origen. Un canal de participación en el proceso fue la Comisión Sectorial del Mercosur (COMISEC). Por fuera del ámbito estatal, se tuvo también al Consejo Industrial del Mercosur (CIM), que brindaba a la Cámara una vía de expresión de dimensiones internacionales. Más allá de estos canales, en el nuevo formato de negociaciones comerciales el Estado desempeñó un papel más preponderante que en la década de 1960.

Si bien el Mercosur impactó fuertemente en las estructuras industriales uruguayas, algunos organismos internacionales influyeron en la estructura organizativa de la CIU y fueron cruciales en su proceso de transformación en una entidad prestadora de servicios de comienzos de los años 1990. El elemento 'desencadenante' fue un proyecto financiado por la Organización de las Naciones Unidas para el Desarrollo Industrial (ONUDI) en 1992, que tuvo continuación en un proyecto financiado por el BID para estudiar oportunidades comerciales en Argentina, Brasil y México. ${ }^{12}$ De este proyecto quedaron en la CIU

\footnotetext{
${ }^{12}$ Entrevista a Roberto Villamil, gerente general de la CIU.
} 
dos unidades apoyadas con fondos del BID: el Servicio de Información para Empresarios (SIPE) y una unidad de capacitación llamada Instituto Industrial de Estudios Superiores (IIES). El BID pasó a ser una de las mayores fuentes de apoyo de la CIU, financiando además servicios de asistencia técnica y orientación en la ejecución de proyectos (CEGETEC), o la formación de "consorcios de exportación". El nexo con el BID se daba también en otros planos, ya que varios ejecutivos (técnicos) que trabajaban en la CIU recibían financiación directa o indirecta de este banco. El apoyo del BID, sin embargo, no fue repentino. Dada la 'fragilidad' de la Cámara en la prestación de servicios, los programas del BID incluían el rubro 'fortalecimiento institucional', que buscaba mejorar la capacidad técnica de la CIU. Otra institución que también en Uruguay se dirigía a los empresarios con programas para las pyme era la GTZ. Su primer proyecto con la CIU comenzó a principio de los años 1990, con el establecimiento de una división de apoyo a las pyme. Al igual que el BID, la GTZ incluyó el 'apoyo institucional' en sus proyectos, lo que concordaba con su política de convertir a las asociaciones empresariales en organizaciones orientadas a servicios. ${ }^{13}$

\section{VI}

\section{Conclusiones}

Este estudio ha examinado el proceso de cambio institucional en Chile y Uruguay, a través de asociaciones de empresarios industriales. Se ha confirmado la hipótesis postulada aquí sobre un aumento de influencia de instituciones y organizaciones de nivel global en la década de 1990. En los años 1960 ya se articulaba la cultura global a través de organismos internacionales que difundían modelos de organización basados en una cultura racional. El apoyo a la 'planificación' estaba, en Chile y Uruguay, asociado a la promoción de un enfoque positivo de 'lo técnico', del Estado y de la democracia. Esta visión se encarnó en el desarrollismo y en la CEPAL, también fuertes impulsores del regionalismo, y tuvo gran influencia en el empresariado industrial, especialmente en Chile. Durante el interludio militar se produjo un corte en lo referente al papel del Estado, los valores democráticos y el regionalismo. Pero se continuó el proceso

\footnotetext{
13 Entrevista a Alfredo Echegaray, especialista sectorial del BID en Uruguay.
}

En Uruguay, como en Chile, la Unión Europea contaba con redes y programas de desarrollo. Uno de ellos, en el cual la CIU (a diferencia de la SFF chilena) tuvo un papel importante, era el eurocentro, que se estableció en la misma Cámara, y promovió activamente los vínculos comerciales entre Uruguay y la Unión Europea. De esta manera la CIU se vinculó también al Sistema de Promoción de Información Tecnológica (TIPS), asociado al Programa de las Naciones Unidas para el Desarrollo (PNUD) y a la Red de Información sobre el Desarrollo (DEVNET) y, entre otras cosas, obtuvo la representación oficial de la 'metodología REFA'. Esto partió de un proyecto financiado por la GTZ en virtud del cual la asociación REFA International ${ }^{14}$ participó en la organización del área educativa de la CIU. En 1998, los pasillos de la Cámara tenían un aspecto muy diferente al de aquel de 1966. Muchas oficinas lucían en sus puertas el nombre de alguna entidad internacional o de algún proyecto con financiación externa. Esto no solo significaba nuevas fuentes de financiación, sino una mayor influencia de fuentes de legitimación no nacionales.

de cambios institucionales por medio de reformas de mercado, sobre todo en Chile. En los años 1990, con la democracia reinstaurada en ambos países, hubo una nueva ola de la cultura global, con mayor presencia de entidades internacionales, fundamentalmente respecto a temas relacionados con el comercio exterior y la promoción de la competitividad. Esto acentuó la importancia del regionalismo, cuya manifestación principal fue el Mercosur. En ambos países se observaron también cambios en las formas de interacción con el Estado, la entidad más relevante del ambiente nacional. Se pasó de una interacción corporativa y subordinada, a una relación basada cada vez más en servicios. Hasta aquí las similitudes, atribuibles en gran medida a cambios sistémicos.

Las diferencias, por su lado, tienen mucho que ver con particularidades institucionales arraigadas en cada

\footnotetext{
14 REFA International es una asociación federal alemana para la organización y capacitación empresariales.
} 
ambiente institucional local. En Uruguay predominan el 'clientelismo' y el 'caudillismo', lo que se asocia a una permanente fragmentación de las políticas públicas y a la dependencia de impulsos individuales dominados por redes con escasa coordinación. Quizás esto explique la débil posición de los técnicos y agentes centralizadores, que desemboca en una posición débil del Estado. Si bien el Estado sigue siendo un elemento fundamental para los industriales, su ausencia ha aumentado. Esto ha dado pie a un papel más relevante de los organismos internacionales, y ha fomentado un proceso de "oenegización" en la CIU. En Chile se mantiene y fortalece el énfasis tecnocrático, que funciona como base de un elitismo que crea puntos de contacto entre la SFF y el Estado. Esto va de la mano con la tradicional tendencia a la centralización, mediante un 'Estado grande' o un 'Estado fuerte'.

El presente estudio muestra que, a pesar de una retórica crecientemente liberal, los empresarios chilenos han ido retomando su estrecha vinculación con el Estado, solo que ahora con un contenido distinto. Respecto a la relación entre Chile y el mundo, diríamos que no es nuevo que este sea un 'país modelo', pues ya en los años 1990 tenía gran correspondencia con la cultura global. Pero sería un error concluir de esto que Chile está en total armonía con 'lo apropiado'. Hay elementos de confrontación con valores de la cultura global, por los cuales la SFF se enfrenta a concepciones menos jerárquicas y elitistas de la sociedad; esto quizás motive su limitado contacto con las organizaciones internacionales, que son vistas con cierta desconfianza. La reacción de la SFF frente al tema de Pinochet es también parte de esa confrontación. Curiosamente, esto la lleva a estrechar los lazos con el Estado, que aparece como un 'aliado' para enfrentar las dimensiones económicas y culturales del proceso de globalización. En este sentido, se ve una ventaja de los uruguayos. El 'caudillismo' y el 'clientelismo' traen consigo una horizontalidad que concuerda más con 'lo apropiado' en la cultura global. Hay allí otras posibilidades de interacción entre el individuo y las elites, tanto a nivel de ciudadano (con respecto al Estado) como en el sector privado. No en vano las jerarquizaciones de países según su carácter democrático siguen ubicando a Uruguay en las más altas posiciones. En síntesis, si se acepta la cultura global como un tipo ideal, se podría decir que Chile tiene una ventaja sobre Uruguay en lo tecnocrático, pero una desventaja en materia de elitismo. En esto Uruguay, por su cultura más horizontal y democrática, está todavía en una mejor posición, aunque cabe señalar que Chile está acortando rápidamente la distancia.

\section{Bibliografía}

Apey Rivera, M.A. (1988): Historia de la Sociedad Nacional de Agricultura, Santiago de Chile, Sociedad Nacional de Agricultura.

Arriagada, G. (1970): La oligarquía patronal chilena, Santiago de Chile, Ediciones Nueva Universidad.

Astori, D. (1980): Los industriales y la tecnología: un análisis, de las actitudes de los empresarios uruguayos, Montevideo, Centro Interdisciplinario de Estudios sobre el Desarrollo (CIEDUR).

Beretta Curi, A. y A.G. Etcheverry (1998): Empresarios y gremiales de la industria. Asomándonos a medio siglo de historia: de la Liga Industrial a la Unión Industrial Uruguaya (1879-1928), Montevideo, Cámara de Industrias del Uruguay (CIU).

Birle, P., P. Imbusch y Ch. Wagner (1994): Los empresarios y la integración regional en America Latina, en P. Birle, P. Imbusch y otros. Dos estudios sobre los empresarios y la integración regional, Montevideo, Fundación Friedrich Ebert (FESUR).

Boli, J. y T.M. Georg (comps.) (1999): Constructing World Culture: International Nongovernmental Organisations since 1875, California, Stanford University Press.

Campero, G. (1984): Gremios empresariales en el período 19701983, Santiago de Chile, Instituto Latinoamericano de Estudios Transnacionales (ILET).

CEPAL (Comisión Económica para América Latina y el Caribe) (1998): Apoyo al Ministerio de Industria, Energía y Minería (MIEM) para la elaboración de estudios en el sector industrial, Proyecto URU/96/011, Santiago de Chile.

Ceppi, M. de L., B. Sanhueza y otros (1983): Chile: 100 años de industria 1883-1983, Santiago de Chile, Sociedad de Fomento Fabril (SFF).
CIDE (Comisión de Inversiones y Desarrollo Económico) (1989): Informe sobre la administración pública, serie Reforma del Estado, $\mathrm{N}^{\circ} 2$, Montevideo, Instituto Nacional del Libro.

CIU (Cámara de Industrias del Uruguay) (1966): Memoria anual 1966-1967, Montevideo.

(1998): Memoria anual 1998-1999, Montevideo, Cámara de Industrias del Uruguay.

El Día (1966): Suplemento "Día de la industria", 12 de noviembre.

El Mercurio (1966): Aporte de 775 millones de dólares de la Alianza para el Progreso, Santiago de Chile, 16 de marzo.

Empresa (1968): año XII, $\mathrm{N}^{\circ} 76$, agosto.

Esser, K., G. Almer y otros (1983): Monetarismo en Uruguay: efectos sobre el sector industrial, Berlín, Instituto Alemán de Desarrollo (IAD).

Faroppa, L.A. (1982): Políticas para una economía desequilibrada: Uruguay 1958-1981, Temas del siglo, Montevideo, Ediciones de la Banda Oriental.

Ferrando, L. (1989): Gremiales empresariales, Unión Industrial Uruguaya. Textos auxiliares para el estudio de la historia, Montevideo, Facultad de Humanidades y Ciencias de la Educación.

Finch, E.A. (1973): The Politics of Regional Integration: a Study of Uruguay's Decision to Join LAFTA, Monograph Series, $\mathrm{N}^{\circ} 4$, Liverpool, Universidad de Liverpool.

Hardt, M. y A. Negri (2000): Empire, Cambridge, Harvard University Press.

Hart, O. (1995): An economist perspective on the theory of the firm, en O. Williamson (comp.), Organization Theory: From Chester Barnard to the Present and Beyond, Oxford, Oxford University Press. 
Hettne, B. y A. Inotai (1997): The new regionalism: implications for global development and international security, Research for Action, Helsinski, Instituto Mundial de Investigaciones de Economía del Desarrollo, Universidad de las Naciones Unidas.

Jacob, R. (1981): Breve historia de la industria en Uruguay, Montevideo, Fundación de la Cultura Universitaria.

Kirsch, W.H. (1977): Industrial Development in a Traditional Society: The Conflict of Modernisation in Chile, Gainesville, The University Presses of Florida.

La Mañana (1966): Síntesis, $N^{\circ} 102,23$ de mayo.

March, J.G. y J.P. Olsen (1989): Rediscovering Institutions. The Organisational Basis of Politics, Nueva York, The Free Press.

MIEM (Ministerio de Industria, Energía y Minería) (1997): 90 años, 1907 - 12 de marzo, 1997, Montevideo.

Mikesell, R.F. (1961): The movement toward regional trading groups in Latin America, en A. Hirschman (comp.), Latin American Issues. Essays and Comments, Nueva York, The Twentieth Century Fund.

Muñoz Gomá, O. (1997): Políticas públicas para un desarrollo competitivo, Santiago de Chile, Editorial Universidad de Santiago.

Powell Walter, W. y P. DiMaggio (comps.) (1991): The New Institutionalism in Organisational Analysis, Chicago, The University of Chicago Press.

Rosenau, J.N. (2003): Distant Proximities. Dynamics beyond Globalization, Princeton, Princeton University Press.
Selznick, Ph. (1949): TVA and the Grass Roots: a Study in the Sociology of Formal Organizations, vol. 3, Berkeley, University of California Press.

SFF (Sociedad de Fomento Fabril) (1966): Memoria anual, 1966-1967, Santiago de Chile, Sociedad de Fomento Fabril.

(1998): Memoria anual, 1998-1999, Santiago de Chile.

Silva, E. (1996): The State and Capital in Chile, Business Elites, Technocrats, and Markets Economics, Colorado, Westview Press.

Silva, V. (2001): Estrategia y agenda chilena en los años noventa, serie Comercio internacional, No 11, LC/L.1550-P, Santiago de Chile, Comisión Económica para América Latina y el Caribe (CEPAL). Publicación de las Naciones Unidas, $\mathrm{N}^{\mathbf{o}}$ de venta: S.01.00.G.94.

Stolovich, L., J.M. Rodríguez y L. Bértola (1996): El poder económico en el Uruguay actual, Montevideo, Centro Uruguay Independiente.

Tironi, E. (1999): La irrupción de las masas y el malestar de las elites: Chile en el cambio de siglo, Santiago de Chile, Editorial Grijalbo S.A.

Zeitlin, M. (1984): The Civil Wars in Chile (or the Bourgeois Revolutions that Never Were), Princeton, Princeton University Press.

Zurbriggen, C. (1999): Las organizaciones empresariales en la escena de los 90, Working Paper, Montevideo, Instituto de Ciencia Política (ICP). 